\title{
Assessment of Land Use and Vegetative Cover in Kano Metropolis (from 1975-2015) Employing GIS and Remote Sensing Technology
}

\author{
${ }^{*}$ M. Haruna, M. K. Ibrahim and U. M. Shaibu \\ Department of Agricultural Economics and Extension, Kogi State University, Anyigba, Nigeria \\ [*Corresponding Author: E-mail: brave.monday@yahoo.com]
}

\section{ABSTRACT}

This study applied GIS and remote sensing technology to assess agricultural land use and vegetative cover in Kano Metropolis. It specifically examined the intensity of land use for agricultural and non agricultural purpose from 1975 - 2015. Images (1975, 1995 and 2015), landsat MSS/TM, landsat 8, scene of path 188 and 052 were downloaded for the study. Bonds for these imported scenes were processed using ENVI 5.0 version. The result indicated five classified features-settlement, farmland, water body, vegetation and bare land. The finding revealed an increase in settlement, vegetation and bare land between 1995 and 2015, however, farmland decreased in 2015. Indicatively, higher percentage of land use for non agricultural purposes was observed in recent time. Conclusively, there is need to accord surveying the rightful place and priority in agricultural planning and development if Nigeria is to be self food sufficient.

Keywords: Geographic Information System, Agriculture, Remote sensing, Land use, Land cover

\section{INTRODUCTION}

It is an established fact that Nigeria is endowed with vast resources (human and natural) necessary for agricultural production. Apparently, agriculture is a major player in the Nigeria economy. Consequently, the folly of relying on an exhaustible and economically unstable resource like oil as a major foreign exchange earner is becoming increasingly glaring. Thus, the need to enhance agricultural productivity for local consumption and export income has been recognized by the present administration (Food and Agriculture Organization, FAO, 2010).

Nearly $75 \%$ of the population In Nigeria are living in rural areas and are still dependent on Agriculture (FAO, 2010). The sector's contribution to the Gross Domestic Product, export earnings, food supply and employment, has not been registering appreciable increase in growth in recent years (National Bureau of Statistics, NBS, 2013). This growth is slowest in the food crop and livestock sectors when compared with export crops. The slow growth rate could be associated with farmers' poor access to support services such as extension, agricultural land information, knowledge, technology and financial credit. The agricultural land information system brings sustainable revolution by empowering the farmers with up-to date knowledge and information about agricultural land and technologies, best practices, markets, price trends, consumer preferences, sources of finance, weather, soil moisture conditions and the environment (Paul et al., 2003).

It is suffice to say that the solution for providing food security to all people of the world without affecting the agroecological balance lies in the adaptation of new research tools, particularly from aerospace Remote Sensing, and combining them with conventional as well as frontier technologies like Geographic Information Systems (GIS). Sustainable agricultural development is one of the prime objectives in all countries of the world, whether developed or developing. The broad objective of sustainable agriculture is to balance the inherent land resource with crop requirements, paying special attention to optimization of resource use towards achievement of sustained productivity over a long period (Lal and Pierce, 1991). Accordingly, Uwe and Stanley (2001) emphasized that GIS is increasingly being used widely in parcel mapping. 


\section{Nigerian Journal of Basic and Applied Science (December, 2019), 27(2): 01-07}

Without proper land registration, formal land markets are less efficient and the incentives to invest in land conservation might be limited. Also, without land titles, farmers often have difficulty accessing credit. In many instances, however, land ownership, access, and use rights may be complex especially where resources are communal. They further stressed that land-titling systems tend to assume that a given piece of land is uniquely assigned to an owner, while in reality it may be subject to a complex web of overlapping, shared uses based on informal, mutually beneficial agreements.

Bhan et al. (2010) pointed out that sustainable agricultural development vis-à-vis sustainable increase in crop production could be achieved by adopting a variety of agricultural technologies, which may be summed up as: improved crop management technology through the use of high yielding, input responsive and soil, climatic and biotic stresses - tolerant crop varieties; suitable cropping systems for different agro-ecological regions based on soil, terrain and climatic suitability; integrated nutrient management for improving soil productivity and minimization of the risk of pollution of soil, water and environment; integrated pest management for effective pests control as well as to reduce the adverse effects of pesticides on environment; soil and water conservation for controlling soil degradation and improving moisture availability; and input use efficiency maximization in terms of economic return with minimal input.

Despite concerted efforts by Nigerian government to sustain the economy through diversification with cognizance on agriculture, a fundamental issue that needs to be adequately addressed is the role of data collection analysis and management in the quest for agricultural improvement. Indicatively, relevant and timely information is needed for programmes conception, planning, implementation, management, and monitoring. Hence, the role of information in guiding current decision-making and future planning cannot be mismatched. For instance, Alagbe et al. (2013) posited that information on land potential (in terms of capability and suitability) and input requirement for the cultivation of various crops are crucial for agricultural improvement. So also is information on crop performance in agricultural fields, crops yield, yield monitoring, and crop infestation.

Land use is the total of all arrangements, activities and inputs that people undertake in a certain land cover type. In contrast land cover is the observed physical and biological cover of the earth's land as vegetation, rocks, waterbody or man-made features (UNFAO, 1997). Lands are used for agricultural or non agricultural purposes. Agricultural use of land involves cultivation of crops, rearing of animal and other agricultural related activities. Interestingly, farmers have long recognized within-field variability in potential productivity (Pinter et al., 2003). Presently, they are now seeking new ways to exploit such variability. Hence, the discovery of more information on soil and plant conditions than was required a decade ago. The accuracy of such information is essential and must also be available at temporal and spatial scales. Past studies indicated that such information is far-fetch in the study area (Daniel and Salami, 2007; Adesina, 2005; Oyinloye et al., 2004 and Salami, 1999). The geographic information systems (GIS) and remote sensing technology has the potential to transform the ways that lands are managed. There is therefore the need to assess the agricultural land use and vegetative cover as an indicator towards achieving increased agricultural production and a sustainable sector.

Classifications abound for land covers. A proportion of the existing classifications are vegetation classifications, broad land cover classifications, or systems related to the description of a specific feature (e.g., agricultural areas). Thus, they are limited in their capacity to define the whole range of possible land cover classes. For instance, the UNESCO Vegetation Classification (designed to serve primarily for vegetation maps at a scale of 1:1000 000), which 
considers only natural vegetation, while all other vegetated areas, such as cultivated areas and urban vegetated areas, are ignored. Other vegetation classifications, even if they consider agricultural areas, do not describe these classes with the same level of detail as used for the natural vegetation ones. The common integrated approach adopted in this study defines vegetative land cover for agricultural and non-agricultural use.

This study therefore assessed agricultural land use and vegetation cover in Kano Metropolis employing GIS and Remote Sensing Technology. Specifically, the study compared the intensity and level of land use for agricultural and nonagricultural uses from 1975 - 2015 in the study area.

\section{MATERIALS AND METHODS}

This study was carried out in Kano Metropolis, Kano State, Nigeria. Kano is the commercial nerve centre of Northern Nigeria and is the third largest city in Nigeria after Lagos and Ibadan. It is the most populous state in Nigeria with an estimated population (based on the 2006 census) of 13,076,892 people (NBS, 2017). The Kano urban area covers $137 \mathrm{~km}^{2}$ and comprises six Local Government Area (LGA). The metropolitan area covers $499 \mathrm{~km}^{2}$ and comprises eight LGAs namely; Kano municipal, Fagge, Dala, Gwale, Tarami, Nasarawa, Ungogo and Kumbotso.

Two types of data were used in this research. Satellite data that comprised of years multitemporal satellite imageries (LANDSAT imageries of 1975, 1995 and 2015) and the ancillary data which included the ground truth data for the LU/LC classes. The ground truth data was in the form of reference points collected using Geographical Positioning System (GPS) for the 2015 image analysis used for image classification and overall accuracy assessment of the classification results.

A medium resolution landsat MSS, TM and Landsat 8 were downloaded from global land cover facility. The scene of path 188 and row 052 was downloaded for Kano metropolis. The images of the year 1975, 1995 and 2015 were downloaded. The bonds for these scenes were imported to ENVI 5.0 version for processing. The bonds were layer stacked and sub-setted to generate the shape file of the study area. The features in the image were classified using a supervised classification method. In supervised classification the features were classified using the elements of visual interpretation of identify homogenous groups of pixels which represent various features or land cover classes of interest. The numerical information in all spectral bands for the pixels comprising these areas are used to train the computer to recognize spectrally similar areas for each class. Five features were classified from the image; they are settlement, farmland, water body, vegetation and bare land.

\section{RESULTS AND DISCUSSION \\ Comparative Analysis of Land Use and Land Cover (1975-2015)}

The result of captured images of land use and land cover in Kano metropolis from 1975 - 2015 are presented in Figures 1, 2, and 3, covering a period of 40 years. Five features were classified from the images. They are settlement, farmland, water body, vegetation and bare land. Findings from the study revealed that from 1975 to 2015 , increased urbanization and human activities such as construction, deforestation, and agriculture greatly contributed over the years to produce different types of land-use change in Kano metropolis, thereby altering the natural environment and creating a human altered environment. All these have a multiplier effect on the land-use/land-cover changes which have taken place in the study area.

Figure 1 shows the land-use/ land-cover distribution pattern in the year 1975. It reveals that vegetation cover occupies $55.5 \%$ of the landuse category in the study area. This was followed by farm land $(25.4 \%)$, bareland $(15.4 \%)$, settlement (3.4\%) and water body (0.3\%). The land-use/land-cover distribution for 1995 in Figure 
2 shows that agricultural land-use occupies more than two-third $(68.1 \%)$ of the land-use category in the study area. That means urban farming forms a very important occupation in this year and it is widely practiced by occupying the largest percentage of land-use in the study area. This is followed by bare land areas which is the second largest land-use and occupies almost one fifth $(19.3 \%)$ of the land-use categories. Vegetation occupies an important position (8.4\%) in the study area. Built-up areas (settlement) and water bodies occupy approximately $4 \%$ and $0.1 \%$ respectively. The 2015 land-use distribution of Kano metropolis shows reduction in agricultural land-use to $40.3 \%$ while settlement $(23.2 \%)$ shows further increases gaining from agriculture land use. Also, the remaining land-use categories of bare land $(22.9 \%)$, vegetation $(13.5 \%)$, and water body $(0.2 \%)$ show a general increase.

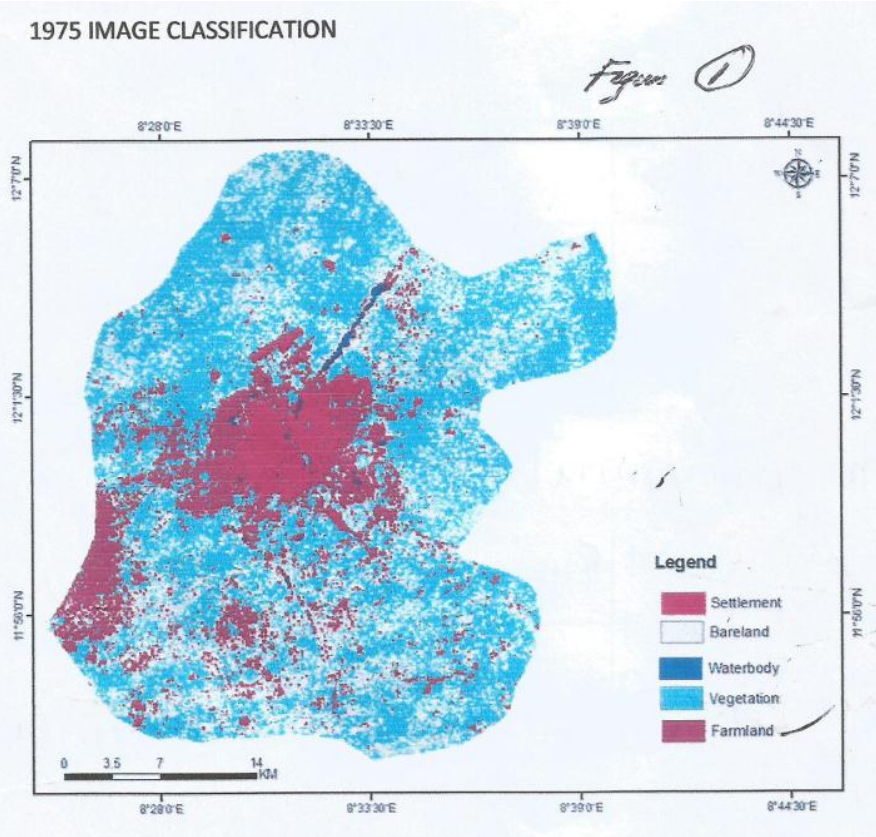

Figure 1: Image Classification of Kano Metropolis in 1975

Level of Land Use for Agricultural and Non agricultural Purpose

The level of land use for agricultural and nonagricultural purpose is presented in Table 1. The categories of land use identified in this study includes, for settlement, for farmland, water body, vegetation cover and bare land.

Settlement: It is evident from Table 1 that there was a $1 \%$ increase in settlement between 1975 and 1995. This was followed by a huge increase (23.18\%) in human settlement in Kano metropolis in 2015. This shows high influx of people between 1995 and 2015. The high increase in percentage of settlement between 1995 and 2015 could be attributed to commercial activities within the study area due to the fact that it is one of the commercial nerve centres in Nigeria. 
Haruna et al: Assessment of Land Use and Vegetative Cover in Kano Metropolis (from 1975-2015).....

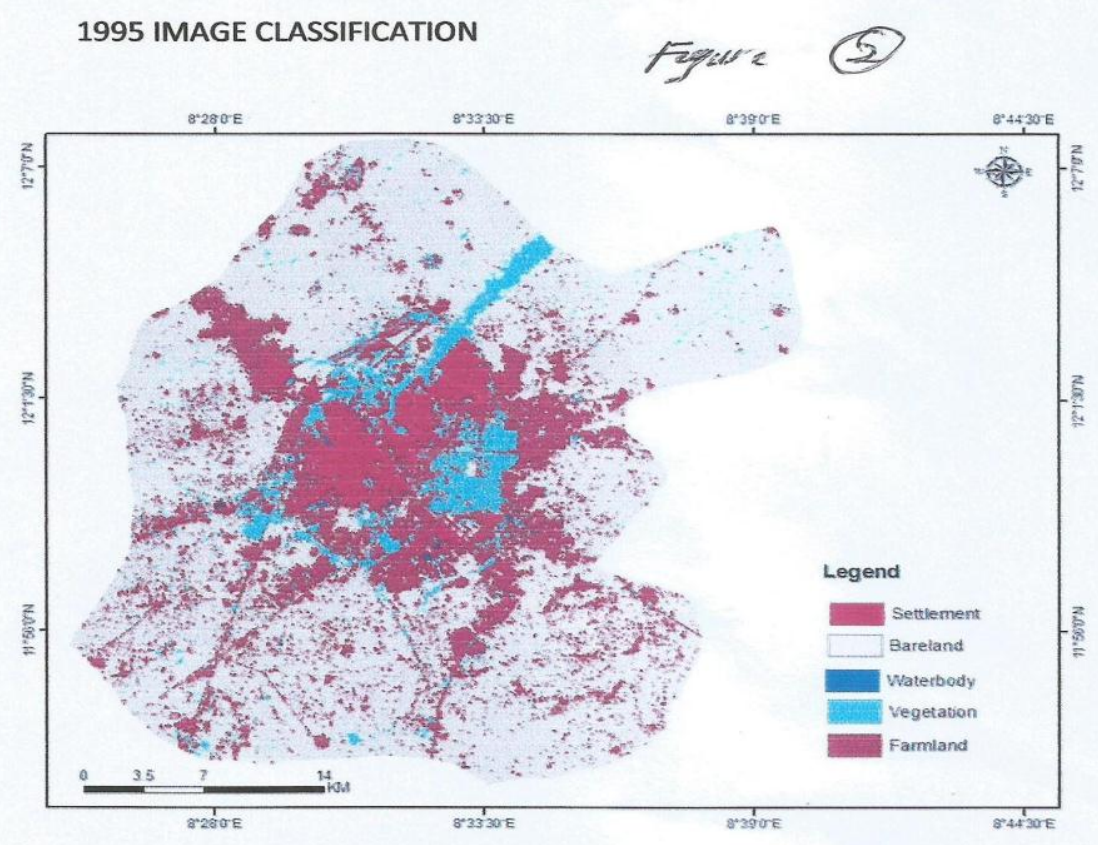

Figure 2: Image Classification of Kano Metropolis in 1995

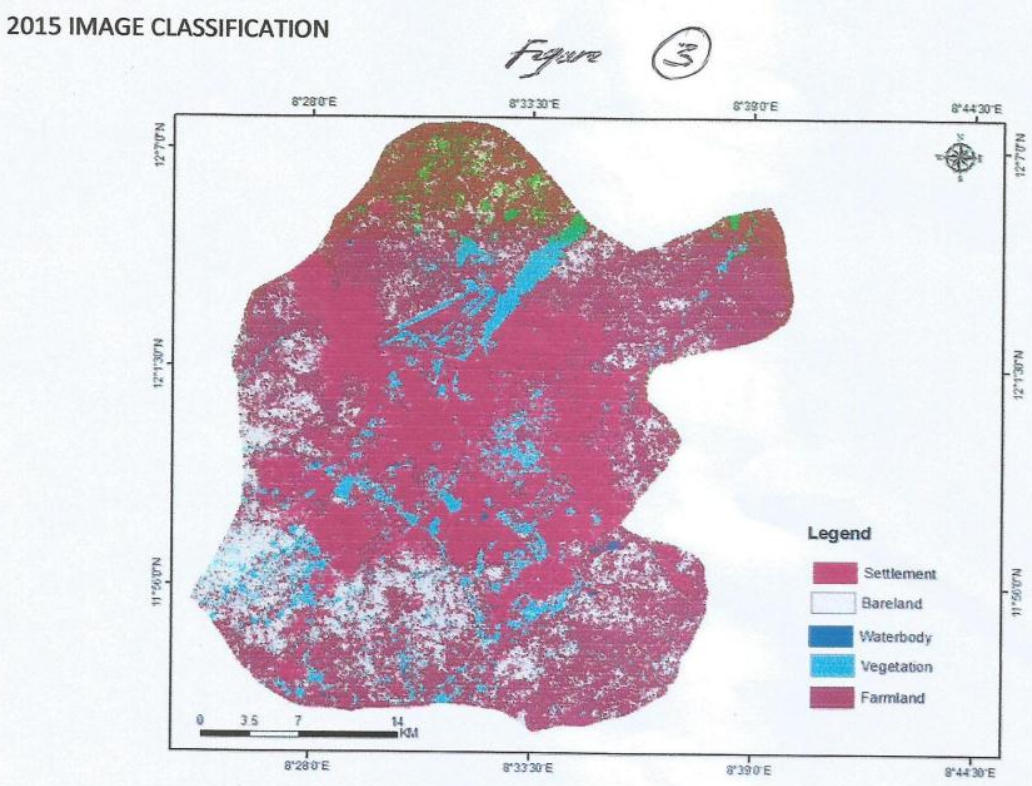

Figure 3: Image Classification of Kano Metropolis in 2015 
Farm land: The results revealed that in terms of employing land for agricultural production, about $12,780.4$ ha was engaged as at 1975 . This increased to $34,141.2$ ha in 1995 . There was a slight decrease in land under agricultural cultivation in 2015 to about $20,197.5$ ha. The decrease in area of land under agricultural production between 1995 and 2015 could be attributed to the huge demand for land for nonagricultural use such as to construct buildings for human settlement

Water body: As observed from the results, the increase and decrease of water body is quite insignificant; $0.30 \%$ in $1975,0.10 \%$ in 1995 and $0.17 \%$ in 2015 . This slight decrease in water body observed across the years could be the result of the growing demand for water for agricultural (such as irrigation farming) and nonagricultural uses.

Vegetation: It is evident from the results that there was large area of vegetation cover in Kano metropolis in 1975. Over the years, there was very significant reduction in the level of vegetation. This reduction is the result of increased demand for land for agricultural and non-agricultural uses.

Bareland: The increasing demand of land for alternative uses and subsequent increase in clearing vegetation cover would ordinarily increase the size of bareland. This is the case in Kano metropolis as demonstrated in the steady increase in area of bareland from 1975-2015.

Table 1: Statistics of Land Use and Vegetation Cover

\begin{tabular}{lllllll}
\hline \multicolumn{1}{c}{ Class } & \multicolumn{1}{c}{$\mathbf{1 9 7 5}$} & \multicolumn{2}{c}{$\mathbf{1 9 9 5}$} & \multicolumn{2}{c}{$\mathbf{2 0 1 5}$} \\
\hline & Area $\left.\mathbf{( k m}^{2}\right)$ & Percentage & Area $\left.\mathbf{( k m}^{2}\right)$ & Percentage & Area $\left(\mathbf{k m}^{2}\right)$ & Percentage \\
Settlement & 1721.88 & 3.42 & 2094.21 & 4.18 & 11622.1 & 23.18 \\
Farm & 12780.4 & 25.41 & 34141.21 & 68.10 & 20197.5 & 40.29 \\
Water body & 148.68 & 0.30 & 49.23 & 0.10 & 85.68 & 0.17 \\
Vegetation & 27895 & 55.46 & 4200.39 & 8.38 & 6771.33 & 13.51 \\
Bare land & 7586.9 & 15.41 & 9647.82 & 19.25 & 11456.25 & 22.86 \\
\hline Total & 50132.86 & 100 & 50132.86 & 100 & 50132.85 & 100 \\
\hline
\end{tabular}

Source: Satellite Data (2016) Figures in parenthesis are in percentages

\section{CONCLUSION}

The findings revealed that the major land-use types in the study area are; built-up environment, cultivated land, waterbody, and bare land. The demand for agricultural and non-agricultural land uses have significantly increased over time and this has greatly depreciated the size of vegetation and waterbody. This study has demonstrated that the recent advancements in remote sensing and GIS technology provides powerful tool for mapping and detecting changes in land use and the results have implications for both the agricultural and non-agricultural sectors. Though, the land use and land cover mapping shown here may not provide the ultimate explanation for all problems related to land use, it serves as a base to understand the patterns and possible cause of the sequence of land use and land cover changes in the area.

\section{REFERENCES}

Adesina, F.A., (2005): Geoinformation and Natural Resources exploitation in Africa; United Nations Economic and Social Council. Paper delivered in Fourth meeting of the committee on Development Information, Addis Ababa on 23-28 April.

Alagbe, J., Afolabi, O.S., Oni, S.O., Udoh, S.I., and Amoo V.O. (2013) Use Of Remote Sensing and GIS Techniques in Assessing Agricultural Land Loss in Abuja, Nigeria. 
Journal of Forestry Research and Management, 10: 40-51

Bhan, S.K., Saha, S.K., Pande, L.M. and Prasad, J. (2010). Use of Remote Sensing and GIS Technology in Sustainable Agricultural Management and Development: Indian Experience. Indian Institute of Remote Sensing, NRSA DEHRADUN-248001, India.

Daniel, A.M. and Salami, A.T. (2007). Application of remote sensing and GIS inland use/land cover mapping and change detection in a part of south western Nigeria. African Journal of Environmental Science and Technology, 1(5): 099-109.

Food and Agriculture Organisations Statistics (FAO), FAOSTAT database, (2010). WDI World Bank, 2010.

Lal, R. and Pierce, M. (1991) - Soil Management for sustainability. Soil and Water Conservation, Ankeny, Iwo, USA.

National Bureau of Statistics (NBS), (2013) Annual Abstract of Statistics, 2013. Federal Republic of Nigeria. Pp 14.

National Bureau of Statistics (2017). Estimated State Population. Retrieved from www.nigerianstat.gov.ng

Oyinloye, R.O., Agbo, B.F., Aliyu, Z.O. (2004). Land Use/Land Cover Mapping in Osun State using NigeriaSat-1 Data. http://www.nasrda.gov.ng/docs/gueye.pdf
Paul, J. Pinter, Jr., Jerry, L. Hatfield, James, S. Schepers, Edward, M. Barnes, M. Susan Moran, Craig, S.T. Daughtry, and Dan, R. U. (2003). Remote Sensing for Crop Management. Photogrammetric Engineering \& Remote Sensing, 69(6): 647-664.

Pinter, P.J. Hatfield, J.L. and Schepers, J.S. (2007). Remote Sensing for Crop Management. Conference of Science Teachers Association of Nigeria (STAN) Pp. 162-165.

Salami, A.T. (1999). Vegetation Dynamics on the fringes of lowland humid tropical rainforest of south western Nigeria- an assessment of environmental change with air photos and LandSat, International Journal of Remote Sensing, 20(6): 1169-1181.

UNFAO (1997) United Nation Food and Agric Organization; online journals. Nigeria National National Population Commission (2006) www.npc.gov.ng.com

Uwe, D. and Stanley, W. (2001). GIS, GPS, and Remote Sensing. 2020 Focus 7 (Appropriate Technology for Sustainable Food), Brief 7 of 9 , August 2001 